Volume 9, No.5, September - October 2020

International Journal of Advanced Trends in Computer Science and Engineering

Available Online at http://www.warse.org/IJATCSE/static/pdf/file/ijatcse110952020.pdf

https://doi.org/10.30534/ijatcse/2020/110952020

\title{
Optimal Distributed Generations Placement in Radial Distribution Network Using Whale Optimization Algorithm
}

\author{
Lee Jin Kang ${ }^{1}$, Syahirah Abd Halim², Hazwani Mohd Rosli ${ }^{3}$, Nor Azwan Mohamed Kamari ${ }^{4}$, \\ Lilik Jamilatul Awalin ${ }^{5}$ \\ ${ }^{1,2,4}$ Department of Electrical, Electronic and Systems Engineering, Universiti Kebangsaan Malaysia, \\ Selangor, Malaysia, jinkang733@gmail.com, syahirah_h@ukm.edu.my, azwank@ukm.edu.my \\ ${ }^{3}$ School of Engineering, Asia Pacific University of Technology \& Innovation, Kuala Lumpur, Malaysia, \\ hazwani@staffemail.apu.edu.my \\ ${ }^{5}$ School of Advanced Technology and Multidisciplinary, Universitas Airlangga, Gedung Nanizar Zaman Joenoes, \\ Surabaya, Indonesia, lilik.j.a@ stmm.unair.ac.id
}

\begin{abstract}
Due to recent high demand of electricity, the usage of distributed generations (DG) in distribution system has been increasing significantly. Distributed generations (DG) are promising solution to conventional energy issues as they are capable of giving many benefits to the efficiency of radial distribution feeders. However, improper placement of DGs will impact the technical aspects of distribution system in term of system voltage instability and power losses. Hence, optimal DGs placement in radial distribution network is very crucial for power loss reduction and voltage performance enhancement. The selection of optimized DGs location in a radial distribution network involves complex optimization problem. Whale Optimization Algorithm (WOA) is proposed to optimize the location of DG units, subjected to the system constraints. First, the system power loss and bus voltage level without DG placement are calculated using power flow analysis based on 'backward-forward' technique. After that, WOA was implemented to determine the optimal placement of DGs on IEEE 28-bus, 33-bus and 69-bus system. The results are then analyzed and compared with other algorithm based on the consistency and convergence characteristics. The power loss reduction and voltage profile improvement within acceptable range has been achieved after placing DG units at optimized location. Also, WOA is reliable optimization technique with high consistency and fast convergence.
\end{abstract}

Key words: Active power loss, distributed generations, optimal placement, whale optimization.

\section{INTRODUCTION}

The utility companies in Malaysia are now facing new challenges where electricity generation needs to be more efficient while also having the characteristics of sustainability and reliability to meet the ever-rising demand for electricity in the future. According to Figure 1, it shows that electricity demand in Peninsular Malaysia is expected to increase by year 2035. However, the increased electricity generation contributes to the high power loss factor in power system. Commercial and industrial consumers in particular will see a significant increase in their electricity bills. Therefore, more electricity needs to be generated to compensate for the increase in consumer load and to reduce the impact of power loss.

Distribution system is more prone to high power loss because it has a higher $\mathrm{R} / \mathrm{X}$ ratio and radial nature of the system [1]. To address this issue, there are various methods that have been introduced by utility companies. One of the most common solution to minimize power loss is the placement of distributed generations (DG) in the radial distribution system. Distributed generation (DG) uses smaller power generating units to produce electricity near the receiving loads of utility thereby avoiding the need for power to be delivered from distant central power stations, suffering losses during transmission. DG can be installed near residential areas, businesses or critical facilities that require high power supply. The capacity of DG are typically between $25 \mathrm{~kW}$ to $100 \mathrm{MW}$ [2].

Solar photovoltaic was chosen as the renewable energy source for DG in this study. The selection factors are based on the availability of photovoltaic cell technology and the climate of Malaysia as Malaysia has a strategic position near the equator [3]. In addition, the total cost of photovoltaic installations is decreasing rapidly, with costs expected to drop even lower towards year 2050 [4]. Distributed generation (DG) is crucial in minimizing power loss, improving grid reliability, providing better voltage profile and improving power quality [5],[6]. DG provides more flexibility and scalability to users as they are easily connected or disconnected from the main power grid. 
Although DG provides many potential benefits to its users, there are still challenges faced by DG during its installation. The main challenge is the improper installation of DG which might leads to the increasing power loss, operating costs and unstable system performance [1],[7]. Therefore, this factor also affects the quality and reliability of power distributed to consumers.

Researchers have studied the use of metaheuristic algorithms to overcome this optimization problem. Oppose to traditional method such as trial and error, the use of metaheuristic optimization algorithms can solve optimization problem in short time with high convergence rate and diversity of solutions [8].

Some metaheuristic optimization methods such as Bacterial Foraging Optimization [9], Lion-Ant Optimization Technique [10], Invasive Weed Optimization [11], Cuckoo Search Algorithm [1] and Flower Pollination Algorithm [12] have been utilized to determine the optimal DG placement in the radial distribution system. In addition, Genetic Algorithm (GA) based on natural evolution can also optimize the location of DG units to minimize power loss [13]. Particle Swarm Optimization (PSO) is another population-based algorithm that has been implemented as the optimization solution to find the placement of multiple DGs in the distribution system [14].

In this paper, the optimization algorithm proposed to obtain the optimal placement of DG in radial distribution network is the newly developed Whale Optimization Algorithm (WOA). This technique is a type of metaheuristics algorithm that tries to be faster and more efficient in solving optimization problems by balancing between local and global search [15]. To the knowledge of author, the consistency and convergence characteristics of this algorithm has yet been validated in solving improper DG placement in power system.

\section{METHODOLOGY}

The methodology of this paper involves three different stages. First, the original power losses and bus voltage level are calculated using 'backward-forward sweep' method. Then, WOA was implemented to optimize the placement of DGs for total active power loss reduction in radial distribution network. Lastly, the result of WOA is compared with PSO to validate the algorithm's performance. Three different case studies based on IEEE 28-bus, 33-bus and 69-bus network are tested with MATLAB software.

\subsection{Objective Function and Constraint}

Given system operating conditions, a single objective function to minimize active power loss has been formulated as shown in (1).

$O F_{\min }=P_{\text {Las }}=\Sigma_{k=1}^{N_{s}}$ Loss $_{k}$

where $O F_{m \text { in }}$ is the objective function, $P_{\text {Los }}$ is the total active power loss, $\operatorname{Lass}_{\mathrm{R}}$ is the power loss at section $k$, and $\mathrm{N}_{s}$ is the number of section.

The power loss in the system is expressed using (2)-(4).

$$
\begin{aligned}
& P_{\text {Lass }}=\sum_{i=1}^{N} \sum_{j=1} X_{i j}\left(P_{i} P_{j}+Q_{i} Q_{j}\right)+Y_{i j}\left(Q_{i} P_{j}+P_{i} Q_{j}\right) \\
& X_{i j}=\frac{R_{i j} \cos \left[\theta_{i}-B_{j}\right]}{V_{i} V_{j}} \\
& Y_{i j}=\frac{\pi_{i j} \sin \left(\theta_{i}-B_{j}\right]}{V_{i} V_{j}}
\end{aligned}
$$

where $P_{1}$ is the active power supplied at bus $i, Q_{i}$ is the reactive power supplied at bus $i, R L_{i j}$ is the line resistance between buses, $V_{i}$ is the voltage at bus $i$ and $\delta_{i}$ is the angle at bus $i$.

Power balance, voltage and current limit constraints are given by (5)-(7) as follows:

$$
\begin{aligned}
& \sum_{i=1}^{W} P_{D G i}=\sum_{i=1}^{N} P_{\text {Ri }}+P_{\text {Las }} \\
& \sum_{i=1} P_{D G i}=\sum_{i=1}^{W} P_{R i}+P_{20 s s} \\
& \left|I_{i j}\right| \leq\left|I_{i j}\right|^{\max }
\end{aligned}
$$

where $P_{D G i}$ is the active power generated by DG at bus $i, P_{A i}$ is the power request at bus $i,\left|V_{i}\right|^{\text {win }}$ is 0.95 per unit and $\left|V_{1}\right|^{\max }$ is 1.05 per unit. According to (8), the total active power generated by DGs were set to a fixed value. Equation (9) is expressed to obtain the active power generation by each DG. Therefore, the DG capacity will change with the number of DGs.

$\sum_{i=1}^{W} P_{D G_{i}}=2.36 \mathrm{MW}$

$P_{D G_{\bar{i}}}=\frac{\sum_{i=1}^{N} P_{b f_{\bar{L}}}}{\text { Number of } D Q}$

\subsection{Whale Optimization Algorithm}

Whale Optimization Algorithm (WOA) is modeled mathematically according to the unique hunting behavior of humpback whales, namely bubble-net hunting method as shown in Figure 1 [15],[16]. 


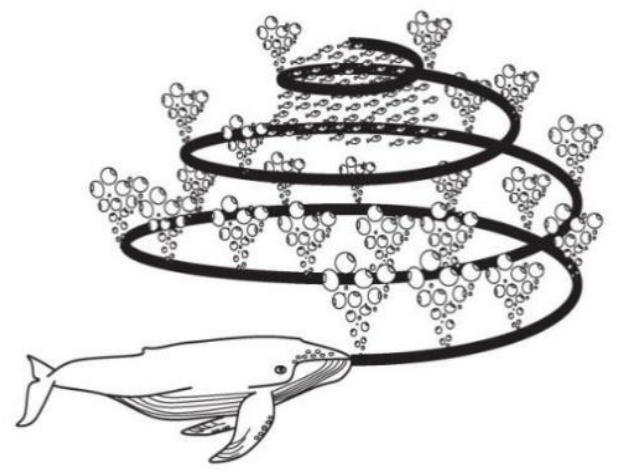

Figure 1: Illustration of whale's hunting behaviour [17]

\subsubsection{Encircling Prey}

The humpback whales encircle around their prey after locating them. In this case, the target prey represents the best solution. After that, the other search agents keep updating their positions towards the best search agent to search for better solution. The equations based on this behaviour are shown below:

$\vec{X}(t+1)=\overrightarrow{X^{*}}(t)-\vec{A} \cdot \vec{D}$

(10)

$\vec{D}=\left|\vec{C} \cdot \overrightarrow{X^{*}}(t)-\vec{x}(t)\right|$

where $\vec{X}$ is position vector of search agent, $\vec{D}$ is distance vector between search agent and best solution, $\vec{X}^{*}(t)$ is position vector of the best solution and $t$ is current iteration. Both coefficient $\vec{A}$ and $\vec{C}$ are computed from (12) and (13) as follows:

$\vec{A}=2 \cdot \vec{a} \cdot \vec{r}-\vec{a}$

(12)

$\vec{C}=2 \cdot \vec{r}$

(13)

\subsubsection{Shrinking Encircling Prey}

To mimic the shrinking encircling prey behavior mathematically, $\vec{A}$ is decreased by linearly reducing the value of $\vec{a}$ from 2 to 0 in (12). Figure 2 shows the possible position of better solution between random search $(X, Y)$ and the current best solution at $\left(X^{*}, Y^{*}\right)$.

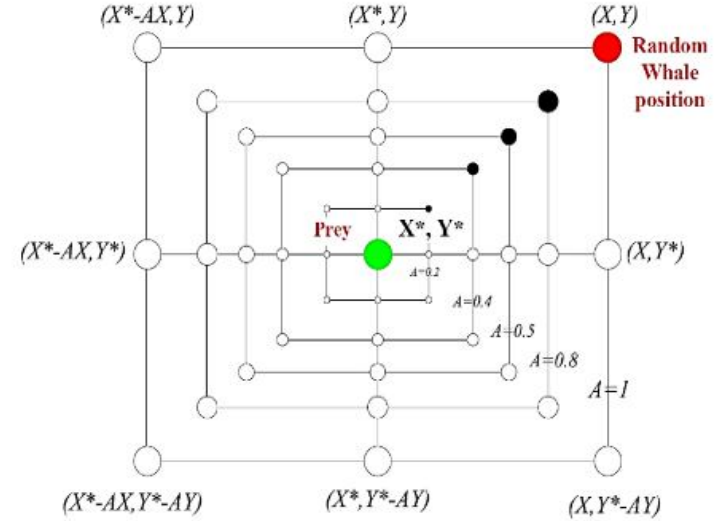

Figure 2: Illustration of shrinking encircling prey approach [14]

\subsubsection{Spirally Position Updating}

In Figure 3, the spirally position updating mechanism first compute the distance between the locations of the whale and prey at $(X, Y)$ and $\left(X^{*}, Y^{*}\right)$ respectively. Then, the helix-shaped movement of the whale is formulated as shown by (14) and (15).

$\vec{X}(t+1)=\vec{D}^{s} \cdot e^{b l} \cdot \cos (2 \pi l)+\vec{X}^{*}(t)$

$\vec{D}^{r}=\left|\vec{X}^{*}(t)-\vec{X}(t)\right|$

where $\vec{D}^{a}$ is distance between search agent and best solution, $b$ is constant describing the helix-shape and $l$ is random number between $[-1,1]$.

However, in real life, the whale swims around its victim in a shrinking circle and spirally along the ' 9 ' shape at the same time. This mathematical model is expressed mathematically in (16), where assuming there is $50 \%$ probability when choosing whether the mechanism is shrinking encircling or spirally position updating during optimization.

$X(t+1)= \begin{cases}\vec{X}^{*}(t)-\vec{A} \cdot \vec{D} & \text { if } p<0.5 \\ \vec{D}^{s} \cdot e^{b l} \cdot \cos (2 \pi l)+\vec{X}^{*}(t) & \text { if } p \geq 0.5\end{cases}$

where $p$ is a random number in interval $[0,1]$. 


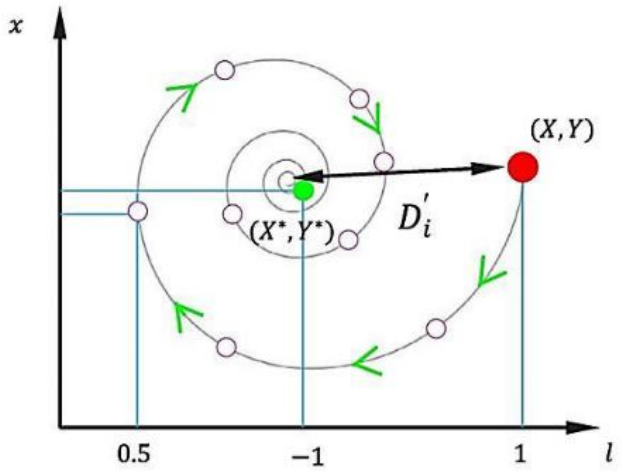

Figure 3: Illustration of spirally position updating approach [16]

\subsubsection{Searching Prey}

To achieve global optimization, the search agent positions are updated by randomly selecting search agent as the prey rather than the best solution. WOA uses the variations of vector $\vec{A}$ to control the search agent to search for solution globally. Equations (17) and (18) show that $\overrightarrow{X_{\text {rand }}}$ has replaced $\vec{X}^{\star}$, where $\overrightarrow{X_{\text {rand }}}$ is the position of random search agent.

$\vec{D}=\left|\vec{C} \cdot \overrightarrow{X_{\text {rand }}}-\vec{X}\right|$

$\vec{X}(t+1)=\overrightarrow{X_{\text {rand }}}-\vec{A} \cdot \vec{D}$

\subsection{Implementation of Whale Optimization Algorithm}

The procedure to implement WOA to install DGs optimally in radial distribution network for active power losses minimization are explained below:

Step 1 Initialize bus data, line data, number of DGs, : $\quad$ population and iteration.

Step 2 Calculate power loss and bus voltage magnitude : before installing DGs using 'backward-forward sweep' technique.

Step 3 Generate initial search agent with random position : $\quad$ (location of DG units).

Step 4 Using (4), determine the fitness function for each : $\quad$ search agent.

Step 5 Vector coefficients $\vec{A}$ dan $\vec{C}$ are updated for each : $\quad$ search agent using (12) and (13).

Step 6 If $p<0.5$, proceed to Step 7. If not, update the : $\quad$ current search agent's position using (14).

Step 7 If $\vec{A}<1$, update the current search agent's position : $\quad$ using (10).
Step 8 If $\vec{A} \geq 1$, update the position of new search agent using (18).

Step 9 When $t>$ maximum number of iterations, display : $\quad$ the results. Otherwise, return to Step 4.

\section{RESULTS AND DISCUSSION}

This section presents the results obtained after successfully implementing WOA on IEEE 28-bus, 33-bus and 69-bus network using MATLAB.

\subsection{Total Active Power Loss}

When one DG unit with $2.36 \mathrm{MW}$ size is installed in the IEEE 28 -bus network, it is placed optimally at bus 1 . This action didn't impact the original active power loss because the DG capacity is too large. However, installation of two DGs and three DGs in this test system reduced the loss from 68.8192 $\mathrm{kW}$ to $48.9097 \mathrm{~kW}$ and $43.8066 \mathrm{~kW}$ respectively.

When the capacity of DG is higher than load bus, the excess power will be transfer to other users instead. This action will compromise the power quality and the system stability as power injection into the distribution network are limited. Therefore, DG size that are not optimized will increase power losses during transmission and distribution.

The increase of number of DG placements from more than three units will instead increase back the total active power loss to a much higher value. This situation is shown when the total loss increased to $46.9955 \mathrm{~kW}$ with the installation of four DG units. Hence, it is proven that the most optimized DGs placement for IEEE 28-bus system is at bus 1,2, and 6 with the size of $0.787 \mathrm{MW}$ for each three DG units as presented in Table 1.

Active power loss without placing any DGs in IEEE 33-bus system is $203.0812 \mathrm{~kW}$. After installation of one DG at bus 6 , the power loss is decreased to $104.8058 \mathrm{~kW}$ with $48.39 \%$ power loss reduction. The gradual increment to the number of DGs has reduced power losses by significant amount. From Table 2, the minimum real power loss is $69.7410 \mathrm{~kW}$ by installing six DG units with the capacity of $0.393 \mathrm{MW}$ at bus $7,10,16,25,30$ and 32.

The result indicates that active power loss reduction percentage increases as the number of DGs increases until seven DG units for IEEE 69-bus system. The placement of seven DGs at bus 12, 21, 60, 61, 62, 63 and 64 with the size of $0.337 \mathrm{MW}$ has achieved the most minimum total real power loss, which is $73.5558 \mathrm{~kW}$ as shown in Table 3 . 


\subsection{Voltage Profile}

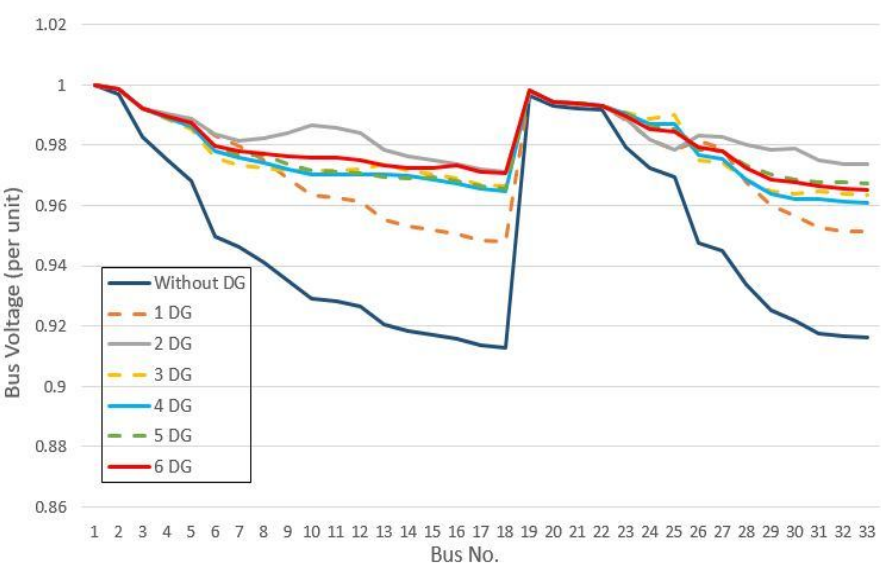

For IEEE 28-bus network with DG installed, the average voltage magnitude is 0.93 per unit. The average voltage level for one DG unit placement remains the same as average voltage level without DG. However, the average voltage level for connection of two DG units and three DG units are increased to 0.9731 per unit and 0.9828 per unit respectively as illustrated in Figure 4.

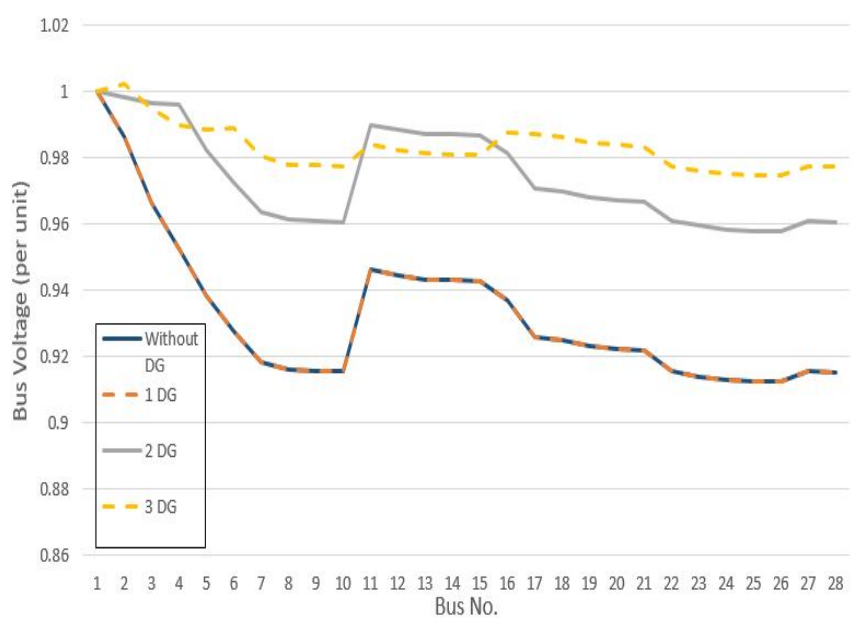

Figure 5: Voltage profile for IEEE 33-bus network

Figure 4: Voltage profile for IEEE 28-bus network

Table 1: Optimal DG location for IEEE 28-bus network

\begin{tabular}{|c|c|c|c|c|}
\hline $\begin{array}{c}\text { Number of } \\
\text { DGs }\end{array}$ & $\begin{array}{c}\text { Total active power } \\
\text { loss (kW) }\end{array}$ & $\begin{array}{c}\text { Power loss } \\
\text { reduction rate }\end{array}$ & $\begin{array}{c}\text { Size for each DG } \\
\text { (MW) }\end{array}$ & $\begin{array}{c}\text { Optimal DG } \\
\text { placement (Bus) }\end{array}$ \\
\hline 0 & 68.8192 & - & - & - \\
\hline 1 & 68.8192 & $0.00 \%$ & 2.360 & 1 \\
\hline 2 & 48.9087 & $28.93 \%$ & 1.180 & 1 \\
& & & & 4 \\
\hline 3 & 43.8066 & $36.35 \%$ & 0.787 & 2 \\
& & & & 6 \\
\hline 4 & 46.9955 & $31.71 \%$ & 0.590 & 1 \\
& & & & 3 \\
& & & & 7 \\
\hline
\end{tabular}

Table 2: Optimal DG location for IEEE 33-bus network

\begin{tabular}{|c|c|c|c|c|}
\hline $\begin{array}{c}\text { Number of } \\
\text { DGs }\end{array}$ & $\begin{array}{c}\text { Total active power } \\
\text { loss (kW) }\end{array}$ & $\begin{array}{c}\text { Power loss } \\
\text { reduction rate }\end{array}$ & $\begin{array}{c}\text { Size for each DG } \\
\text { (MW) }\end{array}$ & $\begin{array}{c}\text { Optimal DG } \\
\text { placement (Bus) }\end{array}$ \\
\hline 0 & 203.0812 & - & - & - \\
\hline 1 & 104.8058 & $48.39 \%$ & 2.360 & 6 \\
\hline 2 & 87.8012 & $56.77 \%$ & 1.180 & 10 \\
& & & & 30 \\
\hline 3 & 75.3344 & $62.90 \%$ & 0.787 & 13 \\
& & & & 25 \\
& & & & 31 \\
\hline 4 & 71.6261 & $64.73 \%$ & 0.590 & 7 \\
\hline
\end{tabular}




\begin{tabular}{|c|c|c|c|c|}
\hline & & & & $\begin{array}{l}14 \\
25 \\
31\end{array}$ \\
\hline 5 & 70.1381 & $65.46 \%$ & 0.472 & $\begin{array}{c}8 \\
15 \\
25 \\
29 \\
32\end{array}$ \\
\hline 6 & 69.7410 & $65.66 \%$ & 0.393 & $\begin{array}{c}7 \\
10 \\
16 \\
25 \\
30 \\
32\end{array}$ \\
\hline
\end{tabular}

Table 3: Optimal DG location for IEEE 69-bus network

\begin{tabular}{|c|c|c|c|c|}
\hline $\begin{array}{c}\text { Number of } \\
\text { DG }\end{array}$ & $\begin{array}{c}\text { Total active power } \\
\text { loss }(\mathbf{k W})\end{array}$ & $\begin{array}{c}\text { Power loss } \\
\text { reduction rate }\end{array}$ & $\begin{array}{c}\text { Size for each DG } \\
\text { (MW) }\end{array}$ & $\begin{array}{c}\text { Optimal DG } \\
\text { placement (Bus) }\end{array}$ \\
\hline 0 & 238.6731 & - & - & - \\
\hline 1 & 95.6066 & $59.94 \%$ & 2.360 & 61 \\
\hline 2 & 88.0188 & $63.12 \%$ & 1.180 & $\begin{array}{l}11 \\
61 \\
\end{array}$ \\
\hline 3 & 77.1413 & $67.68 \%$ & 0.787 & $\begin{array}{l}12 \\
61 \\
62\end{array}$ \\
\hline 4 & 75.5769 & $68.33 \%$ & 0.590 & $\begin{array}{l}17 \\
60 \\
61 \\
62\end{array}$ \\
\hline 5 & 75.0342 & $68.56 \%$ & 0.472 & $\begin{array}{l}18 \\
59 \\
61 \\
62 \\
64\end{array}$ \\
\hline 6 & 74.4722 & $68.80 \%$ & 0.393 & $\begin{array}{l}18 \\
60 \\
61 \\
62 \\
64 \\
66\end{array}$ \\
\hline 7 & 73.5558 & $69.18 \%$ & 0.337 & $\begin{array}{l}12 \\
21 \\
60 \\
61 \\
62 \\
63 \\
64\end{array}$ \\
\hline
\end{tabular}




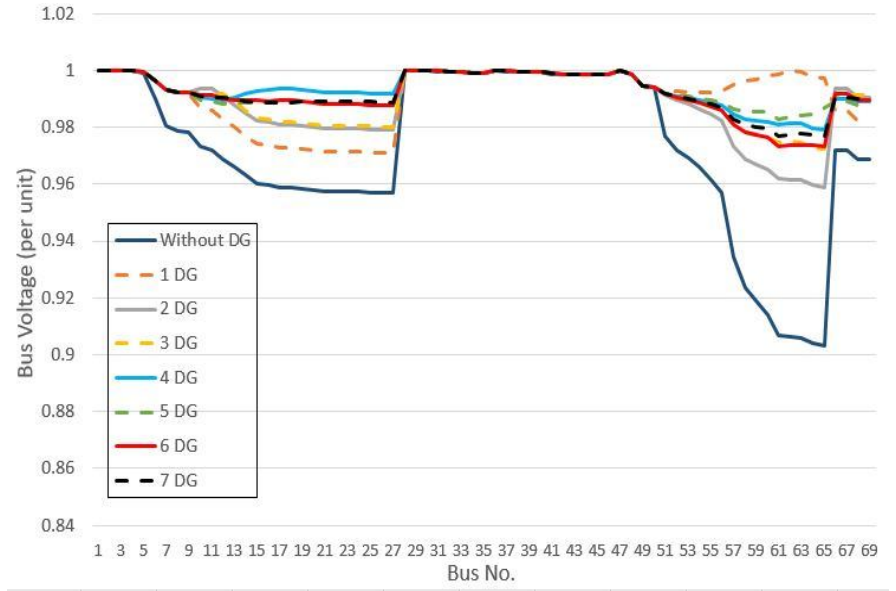

Figure 6: Voltage profile for IEEE 69-bus network

In Figure 5, the voltage profile for optimized placement of one DG until six DGs in IEEE 33-bus network are presented. When no DG units are installed, the average bus voltage is 0.9484 per unit and lowest voltage magnitude is 0.9129 per unit at bus 18 .

After installation of one DG, the average bus voltage increased to 0.9727 per unit while minimum bus voltage also increased to 0.9479 per unit at bus 18 . When the number of DG increases, the average voltage level is increased to 0.9836 per unit (two DGs), 0.9781 per unit (three DGs), 0.9782 per unit (four DGs), 0.97913 per unit (five DGs) and 0.9800 per unit (six DGs).

According to Figure 6, the average bus voltage before installing DG in IEEE 69-bus network is 0.9725 per unit. The optimal placement of seven DG units increased the average voltage magnitude to 0.9922 per unit. Therefore, the results of all three case studies shown that installing DGs at optimized location enhanced the system voltage performance.

\subsection{Validation of Algorithm Performance}

The performance of WOA based on consistency, convergence characteristics and optimal DG placement are verified by comparing the simulation results with Particle Swarm Optimization (PSO). The consistency and convergence characteristics tests are conducted with simulation parameter in Table 4.

Table 4: Simulation parameter for consistency and convergence characteristics test

\begin{tabular}{|c|c|}
\hline Parameter & Value \\
\hline Number of search agents & 20 \\
\hline Nuber of iterations & 100 \\
\hline Number of DGs & 3 \\
\hline Number of runs & 20 \\
\hline
\end{tabular}

\subsubsection{Consistency}

Figure 7 shows that WOA gives consistent results at lowest fitness value which is $43.8066 \mathrm{~kW}$ for every run compared to PSO which gives 15 out of 20 consistent results for the same fitness value.

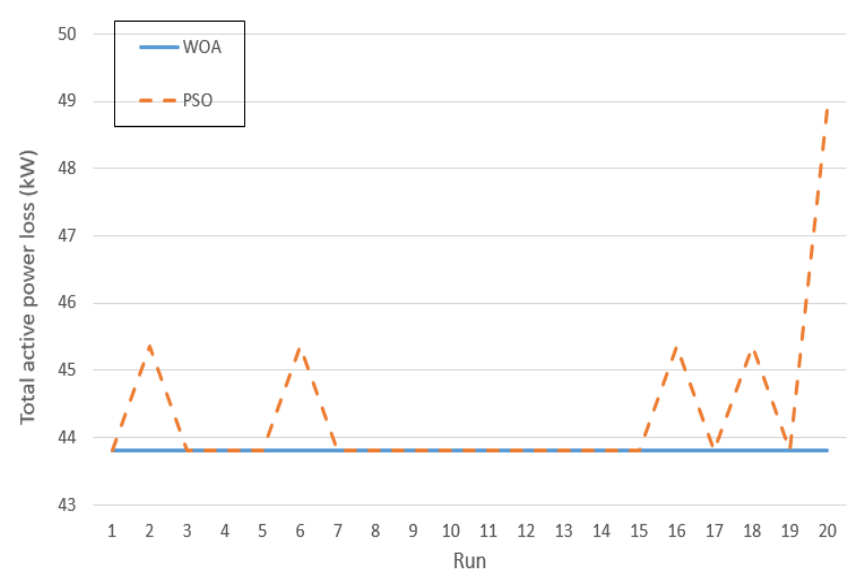

Figure 7: Consistency of WOA and PSO for IEEE 28-bus network

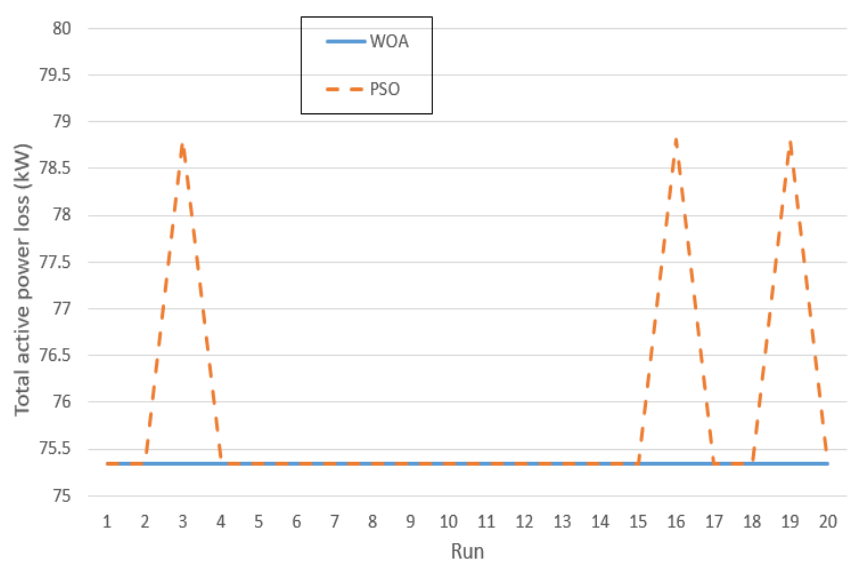

Figure 8: Consistency of WOA and PSO for IEEE 33-bus network

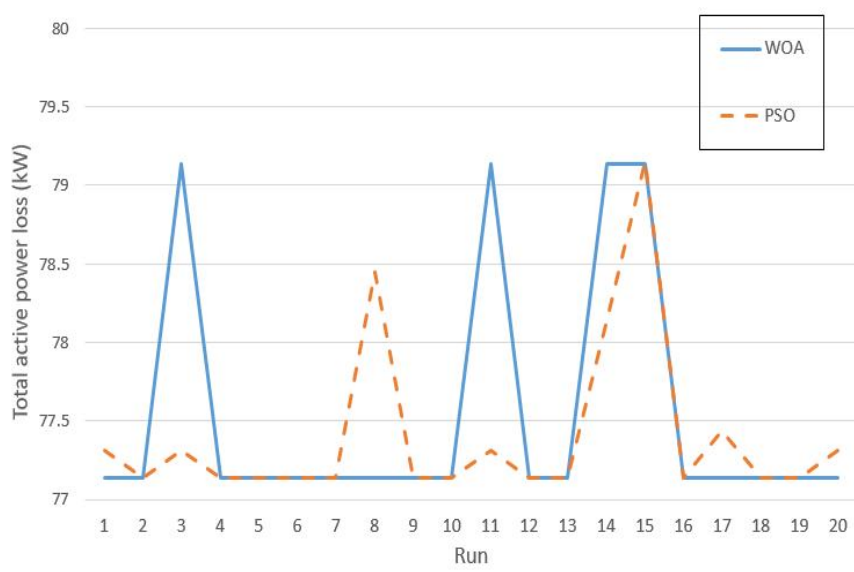

Figure 9: Consistency of WOA and PSO for IEEE 69-bus network

From Figure 8, the lowest fitness value is $75.3344 \mathrm{~kW}$ for optimized three DGs placement in 33-bus system. WOA gives 19 out of 20 consistent results at lowest fitness value as 
compared to PSO which gives 17 out of 20 consistent results. In Figure 9, WOA gives the minimum active power loss of $77.1413 \mathrm{~kW}$ for 16 out of 20 runs. However, PSO gives the same consistent results for 12 out of 20 runs. Hence, overall results shown that WOA produced more consistent results than PSO for all three radial distribution network.

\subsubsection{Convergence Characteristics}

In Figure 10, WOA reaches minimum total real power loss at 5th iteration while PSO reaches at 26th iteration for IEEE 28-bus network. For IEEE 33-bus system, WOA reaches minimum real power losses at 10th iteration while PSO reaches at 25th iteration as presented in Figure 11.

Meanwhile in Figure 12, WOA reaches minimum total active power loss at 14th iteration while PSO reaches at 21st iteration for IEEE 69-bus system. Therefore, WOA has demonstrated faster convergence rate than PSO.

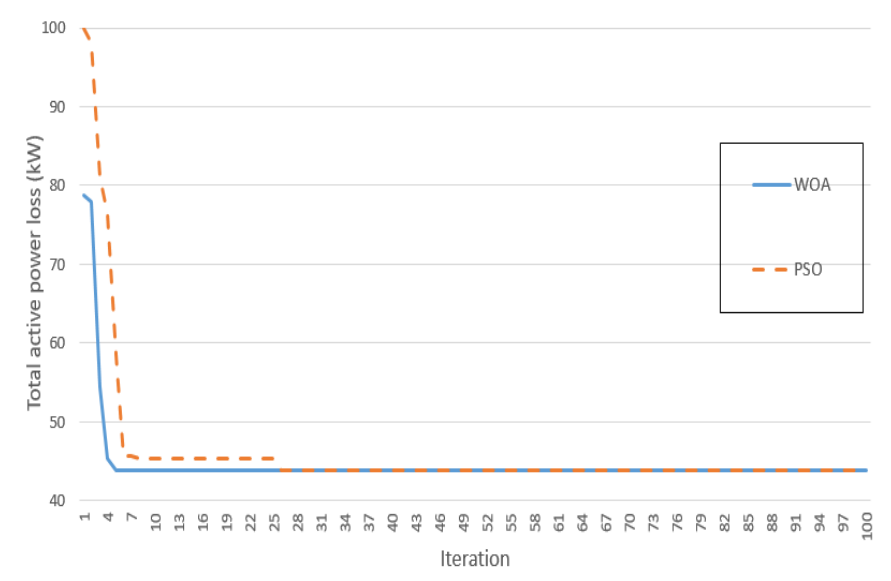

Figure 10: Convergence characteristics of WOA and PSO for IEEE 28-bus network

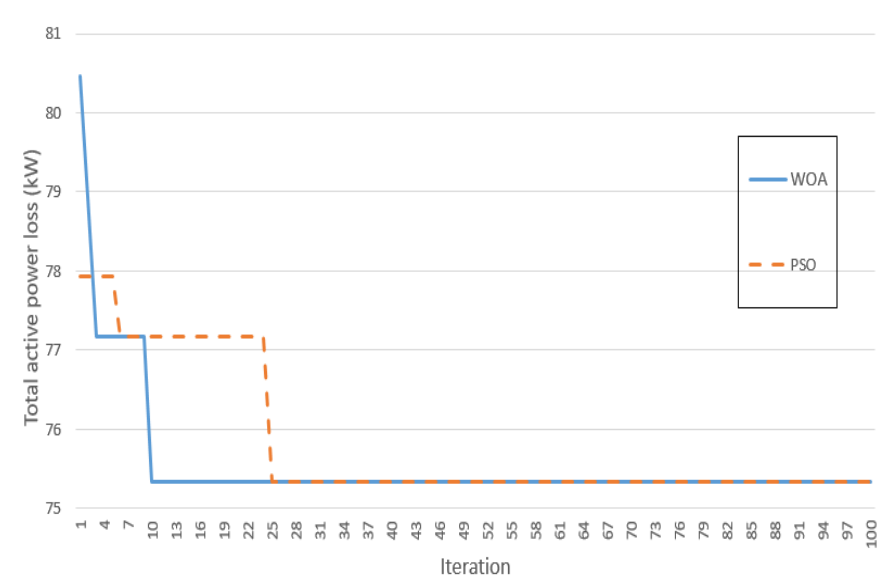

Figure 11: Convergence characteristics of WOA and PSO for IEEE 33-bus network

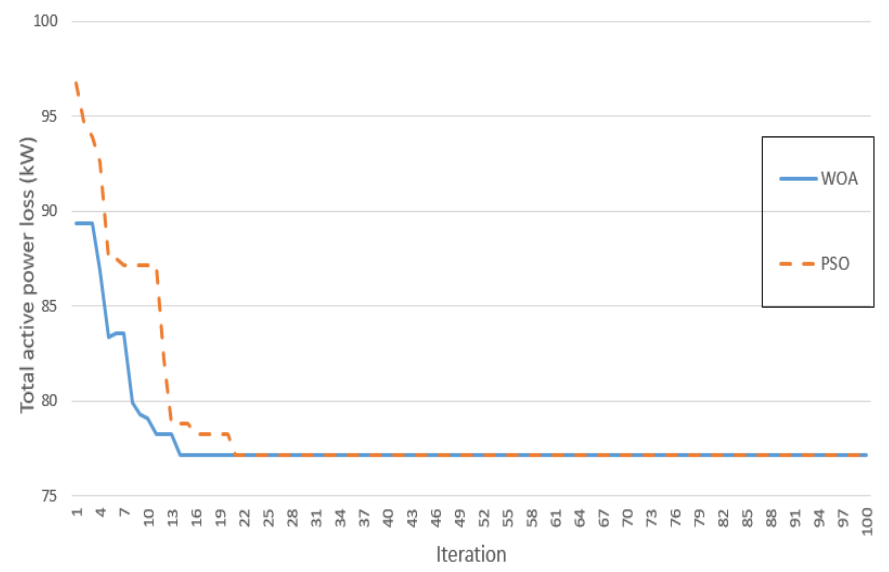

Figure 12: Convergence characteristics of WOA and PSO for IEEE 69-bus network

\subsubsection{Optimal Distributed Generations' Placement}

Table 5 shows the total active power loss corresponds to DGs location obtained by both algorithms are the same for 28-bus network.

WOA compute that installation of six DGs at bus 7, 10, 16, 25,30 and 32 which reduces $65.66 \%$ from the original active power loss is the most optimized solution for IEEE 33-bus network. On the other hand, PSO acquired optimal DG locations at bus $7,11,16,25,30$ and 32 which reduces $65.54 \%$ of the original active power loss as shown in Table 6.

Referring to Table 7, the most optimized solution obtained by WOA for IEEE 69-bus radial distribution is optimal placement of seven DGs which decreases the total active power loss to $73.5558 \mathrm{~kW}$. This value is lesser when compared with the most optimized solution obtained by PSO.

Hence, the results proved that WOA is capable of giving optimization solution that is better than PSO as the radial distribution network configuration becomes larger. Besides that, the computational time taken by WOA is shorter than PSO for all 3 study cases. Therefore, WOA is a fast and capable algorithm in solving optimization problem.

Table 5: Comparison of optimal DG location between WOA and PSO for IEEE 28-bus network 


\begin{tabular}{|c|c|c|c|c|c|c|}
\hline Algorithm & $\begin{array}{c}\text { Total } \\
\text { active } \\
\text { power loss } \\
\text { (kW) }\end{array}$ & $\begin{array}{c}\text { Power loss } \\
\text { reduction } \\
\text { rate }\end{array}$ & $\begin{array}{c}\text { Size } \\
\text { for } \\
\text { each } \\
\text { DG } \\
\text { (MW) }\end{array}$ & $\begin{array}{c}\text { Number } \\
\text { of DGs }\end{array}$ & $\begin{array}{c}\text { Optimal DG } \\
\text { location } \\
\text { (Bus no. })\end{array}$ & $\begin{array}{c}\text { Computational } \\
\text { time (seconds) }\end{array}$ \\
\hline WOA & 43.8066 & $36.35 \%$ & 0.787 & 3 & 1 & 15.58935 \\
& & & & & 2 & \\
\hline PSO & 43.8066 & $36.35 \%$ & 0.787 & 3 & 1 & 16.17732 \\
& & & & & 6 & \\
\hline
\end{tabular}

Table 6: Comparison of optimal DG location between WOA and PSO for IEEE 33-bus network

\begin{tabular}{|c|c|c|c|c|c|c|}
\hline Algorithm & $\begin{array}{c}\text { Total } \\
\text { active } \\
\text { power loss } \\
(\mathbf{k W})\end{array}$ & $\begin{array}{c}\text { Power loss } \\
\text { reduction } \\
\text { rate }\end{array}$ & $\begin{array}{c}\text { Size } \\
\text { for } \\
\text { each } \\
\text { DG } \\
\text { (MW) }\end{array}$ & $\begin{array}{l}\text { Number } \\
\text { of DGs }\end{array}$ & $\begin{array}{c}\text { Optimal DG } \\
\text { location } \\
\text { (Bus no.) }\end{array}$ & $\begin{array}{l}\text { Computational } \\
\text { time (seconds) }\end{array}$ \\
\hline WOA & 69.741 & $65.66 \%$ & 0.3933 & 6 & $\begin{array}{c}7 \\
10 \\
16 \\
25 \\
30 \\
32\end{array}$ & 16.33415 \\
\hline PSO & 69.7747 & $65.64 \%$ & 0.3933 & 6 & $\begin{array}{c}7 \\
11 \\
16 \\
25 \\
30 \\
32\end{array}$ & 16.639735 \\
\hline
\end{tabular}

Table 7: Comparison of optimal DG location between WOA and PSO for IEEE 69-bus network

\begin{tabular}{|c|c|c|c|c|c|c|}
\hline Algorithm & $\begin{array}{c}\text { Total } \\
\text { active } \\
\text { power loss } \\
(\mathbf{k W})\end{array}$ & $\begin{array}{l}\text { Power loss } \\
\text { reduction } \\
\text { rate }\end{array}$ & $\begin{array}{c}\text { Size } \\
\text { for } \\
\text { each } \\
\text { DG } \\
\text { (MW) }\end{array}$ & $\begin{array}{c}\text { Number } \\
\text { of DGs }\end{array}$ & $\begin{array}{l}\text { Optimal DG } \\
\text { location } \\
\text { (Bus no.) }\end{array}$ & $\begin{array}{l}\text { Computational } \\
\text { time (seconds) }\end{array}$ \\
\hline WOA & 73.5558 & $69.18 \%$ & 0.3377 & 7 & $\begin{array}{l}12 \\
21 \\
60 \\
61 \\
62 \\
63 \\
64\end{array}$ & 26.952965 \\
\hline PSO & 75.1789 & $68.50 \%$ & 0.3933 & 6 & $\begin{array}{l}18 \\
60 \\
61 \\
63 \\
64 \\
69\end{array}$ & 26.989885 \\
\hline
\end{tabular}




\section{CONCLUSION}

In conclusion, the power loss reduction and voltage profile improvement within acceptable range has been achieved after DG units are installed at optimized location for IEEE 28-bus, 33-bus and 69-bus system using Whale Optimization Algorithm. Besides that, WOA demonstrated high consistency and fast convergence characteristics of in obtaining better solution for optimal placement of DGs in radial distribution network.

\section{ACKNOWLEDGEMENT}

The authors thank the Ministry of Education Malaysia (MOE) and the National University of Malaya (UKM) for supporting this work through FRGS research grant (FRGS/1/2018/TK04/UKM/02/12).

\section{REFERENCES}

1. Sudabattula, S, Kowsalya, M. Optimal Allocation of Wind Based Distributed Generators in Distribution System Using Cuckoo Search Algorithm, Procedia Computer Science, Vol. 92, pp. 298-304.

2. Sahito, AA, Kalhoro, SD, Mahar, MA, Memon, MU, Lashari, IA. Distribution System Power Loss Reduction through Distributed Generation, Sindh University Research Journal, Vol. 49, pp. 55-58.

3. Almaktar M, Abdul Rahman H, Hassan MY, Wan Omar WZ. Photovoltaic technology in Malaysia: past, present, and future plan, International Journal of Sustainable Energy, Vol. 34, pp. 128-140.

4. Gielen, D, Boshell, F, Saygin, D, Bazilian, MD, Wagner, $\mathrm{N}$, Gorini, R. The role of renewable energy in the global energy transformation, Energy Strategy Reviews, Vol. 24, pp. 38-50.

5. Dulău, LI, Abrudean, M, Bică, D. Optimal Location of a Distributed Generator for Power Losses Improvement, Procedia Technology, Vol. 22, pp. 734-739.

6. Halim, SA, Rosli, HM, Hasri, HF. Moth-Flame Optimization Algorithm with Different Course for Optimal Photovoltaic Location and Sizing, International Journal of Advanced Trends in Computer Science and Engineering, Vol. 8, pp. 145-152.

7. Kamil, K, Chong, KH, Hashim, H. Impact of High Penetration of Solar PV Output to Line Loading, Voltage and Power Losses, International Journal of Advanced Trends in Computer Science and Engineering, Vol. 8, pp. 361-367.

8. Yang, XS. Metaheuristic optimization, Scholarpedia. Vol. 6, pp. 11472.

9. Devabalaji KR, Ravi, K. Optimal size and siting of multiple DG and DSTATCOM in radial distribution system using Bacterial Foraging Optimization
Algorithm, Ain Shams Engineering Journal, Vol. 7, pp. 959-971.

10. Hadidian-Moghaddam, MJ, Arabi-Nowdeh, S, Bigdeli, M, Azizian, D. A multi-objective optimal sizing and siting of distributed generation using ant lion optimization technique, Ain Shams Engineering Journal, Vol. 9, pp. 2101-2109.

11. Rama Prabha, D, Jayabarathi, T. Optimal placement and sizing of multiple distributed generating units in distribution networks by invasive weed optimization algorithm, Ain Shams Engineering Journal. Vol. 7, pp. 683-694.

12. Sudabattula, S, Kowsalya, M. Distributed Energy Resources Allocation Using Flower Pollination Algorithm in Radial Distribution Systems, Energy Procedia, Vol. 103, pp. 76-81.

13. Singh, B, Singh, S. GA-based optimization for integration of DGs, STATCOM and PHEVs in distribution systems, Energy Reports, Vol. 5, pp. 84-103.

14. Prakash, DB, Lakshminarayana, C. Multiple DG Placements in Distribution System for Power Loss Reduction Using PSO Algorithm, Procedia Technology, Vol. 25, pp. 785-792.

15. Mirjalili, S, Lewis, A. The Whale Optimization Algorithm, Advances in Engineering Software, Vol. 95, pp. 51-67.

16. Zakaria, NA, Zain, AM, Latib, AA, Subari, K. Application of whale optimisation algorithm in injection moulding process, International Journal of Advanced Trends in Computer Science and Engineering, Vol. 8, pp. 130-134.

17. Ismael, SM, Abdel Aleem, SHE, Abdelaziz, AY. Optimal conductor selection in radial distribution systems using whale optimization algorithm, Journal of Engineering Science and Technology, Vol. 14, pp. 87-107. 